\title{
DORSAL BRANCHES OF ABDOMINAL AORTA IN THE RABBIT AND THE EUROPEAN HARE
}

\author{
Flešárová S., Maženský, D. \\ Department of Anatomy, Histology and Physiology \\ University of Veterinary Medicine and Pharmacy, Komenského 73, 04181 Košice \\ The Slovak Republic \\ slavka.flesarova@uvlf.sk
}

\section{ABSTRACT}

The aim of this study was to describe the anatomical arrangement of the branches arising from the dorsal surface of the aorta abdominalis in the rabbit and the hare. The study was carried out on ten adult rabbits and ten adult European hares using the corrosion technique. After the euthanasia, the vascular network was perfused with saline. After polymerization of the casting medium, the maceration was carried out in a $\mathrm{KOH}$ solution. We found different variations in; the number of arteries, level of their origin and arrangement. The aa. lumbales of the same level arose by means of a common trunk or their origin was independent. The aa. lumbales VI or aa. lumbales VI et VII originated also from the a. sacralis mediana. By aa. lumbales we found an important interspecies difference in; number, diameter, ramification and density of dorsal branches, which are designated for the dorsal muscles of the body stem. All listed parameters of branches were higher in the hare. This anatomical arrangement of dorsal branches is adapted to the higher movement activity of the hare. According to our results, it can be concluded that the anatomical arrangement of the branches of the aorta abdominalis shows a higher number of variations in the domesticated rabbit in comparison with the hare.

Key words: abdominal aorta; a. sacralis mediana; aa. lumbales, hare; rabbit

\section{INTRODUCTION}

One of the most frequently occurring wild animals in Europe is the European hare. Despite its relatively abundant occurrence, there is a significant gap of knowledge about its anatomy in the literature. Up to now, the works dealing with the study of the arterial system in the European hare have only been published sporadically [3], [4].

Variations in the origin, branching and course of several arteries have long received attention of anatomists, surgeons and particularly vascular specialist. The variations in the arterial system of several species are the object of interest in a large number of studies [8]. The arterial arrange- 
ment of the branches arising from the aorta abdominalis was studied in several experimental animals, such as; dogs [1], cats [2], rabbis [5], rats [17] and guinea pigs [15].

The aim of this study was to compare the variations of the aorta abdominalis branches arising from its dorsal surface in the domesticated rabbit and the European hare.

\section{MATERIALS AND METHODS}

This study was carried out on 10 adult European hares (Lepus Europaeus, L. 1758, age 140 days) and on 10 adult rabbits (Oryctolagus cuniculus f. domestica, L. 1758, age 140 days). We used hares (obtained from ISFA APRC, Nitra, Slovak Republic) of both sexes (female $n=5$; male $n=5$ ) with a weight range of $2.5-3.2 \mathrm{~kg}$ and New Zealand White rabbits (obtained from HYLAPA s.r.o., Prešov, Slovak Republic) of both sexes (female $n=5$; male $n=5$ ) with a weight range of $1.8-2.3 \mathrm{~kg}$ in an accredited experimental laboratory of the University of Veterinary Medicine and Pharmacy in Kosice. The animals were kept in cages under standard conditions (temperature $15-20^{\circ} \mathrm{C}$, relative humidity $45 \%$, 12-hour light period), and fed with a granular feed mixture (O-10 NORM TYP, Spišské kŕmne zmesi, Spišské Vlachy,
Slovak Republic). The drinking water was available to all animals ad libitum. The animals were injected intravenously with heparin (50000 IU. $\mathrm{kg}^{-1}$ ) $30 \mathrm{~min}$ before they were sacrificed by intravenous injection of embutramide (T-61, $\left.0.3 \mathrm{ml} . \mathrm{kg}^{-1}\right)$. Immediately after euthanasia, the vascular network was perfused with a physiological solution [10]. During manual injection through the ascending aorta, the right atrium of the heart was opened in order to lower the pressure in the vessels in order to ensure an optimal injection distribution. Batson's corrosion casting kit No. 17, using a volume of $50 \mathrm{ml}$ (Dione, České Budějovice, Czech Republic) was used as the casting medium. The maceration was carried out in a $2-4 \% \mathrm{KOH}$ solution for a period of 5 days at $60-70^{\circ} \mathrm{C}$. This study was carried out under the authority of decision No. 2647/07-221/5.

\section{RESULTS}

The paired aa. lumbales arose from the dorsal surface of the aorta abdominalis as segmental vessels. They supplied the; lumbar spinal cord, lumbar vertebrae, muscles of the back, inner lumbar muscles and skin of the back. In the rabbit, the independent origin of the aa. lumbales was pres-

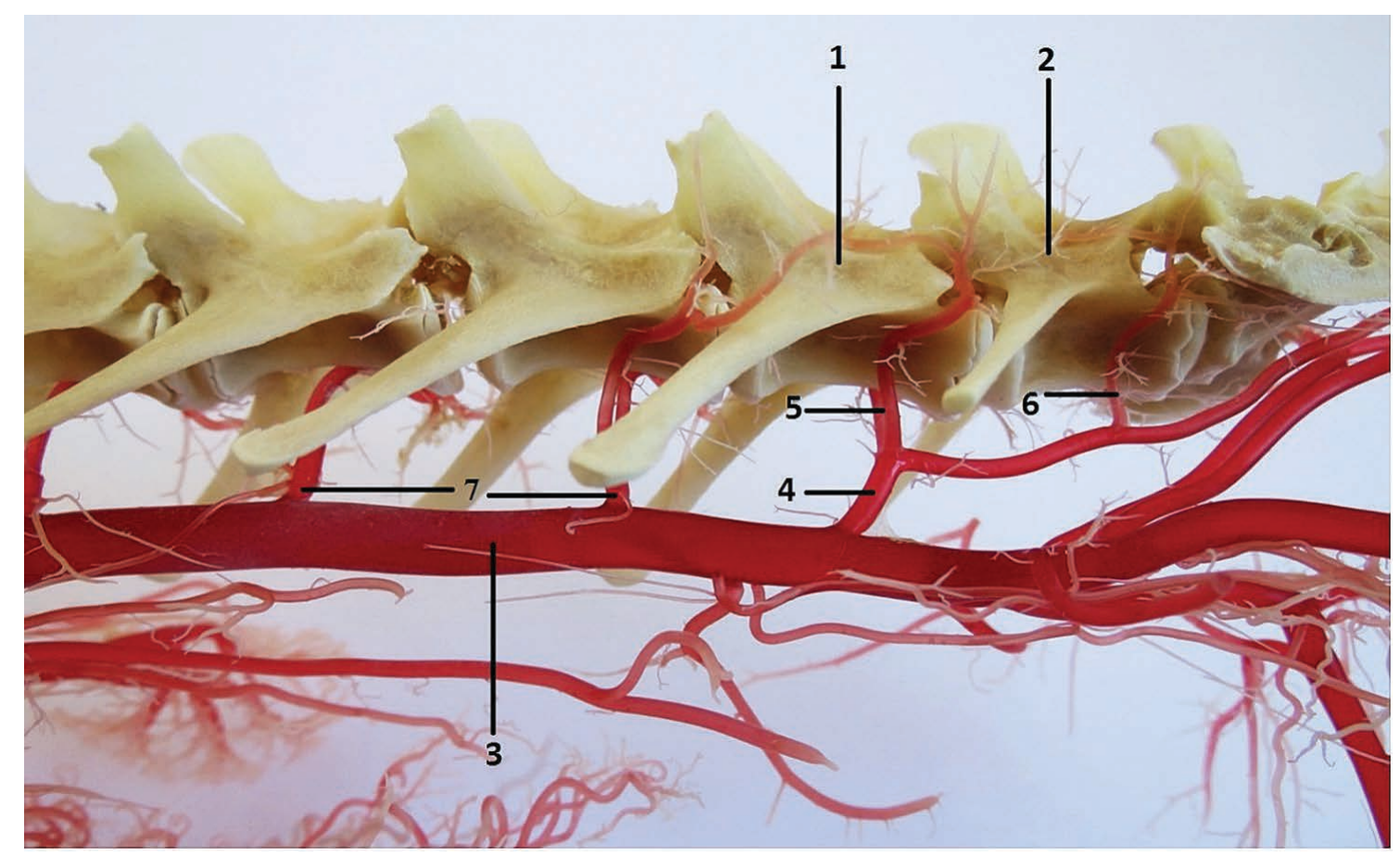

Fig. 1. Aa. lumbales and a. sacralis mediana in the rabbit. Origin of aa. lumbales VI et VII from a. sacralis mediana. 1 - vertebra lumbalis VI; 2 - vertebra lumbalis VII; 3 - aorta abdominalis; 4 - a. sacralis mediana; 5 - aa. lumbales VI; 6 - aa. lumbales VII; 7-common trunk for aa. lumbales $\mathrm{V}$ et IV. Macroscopic image, lateral view 


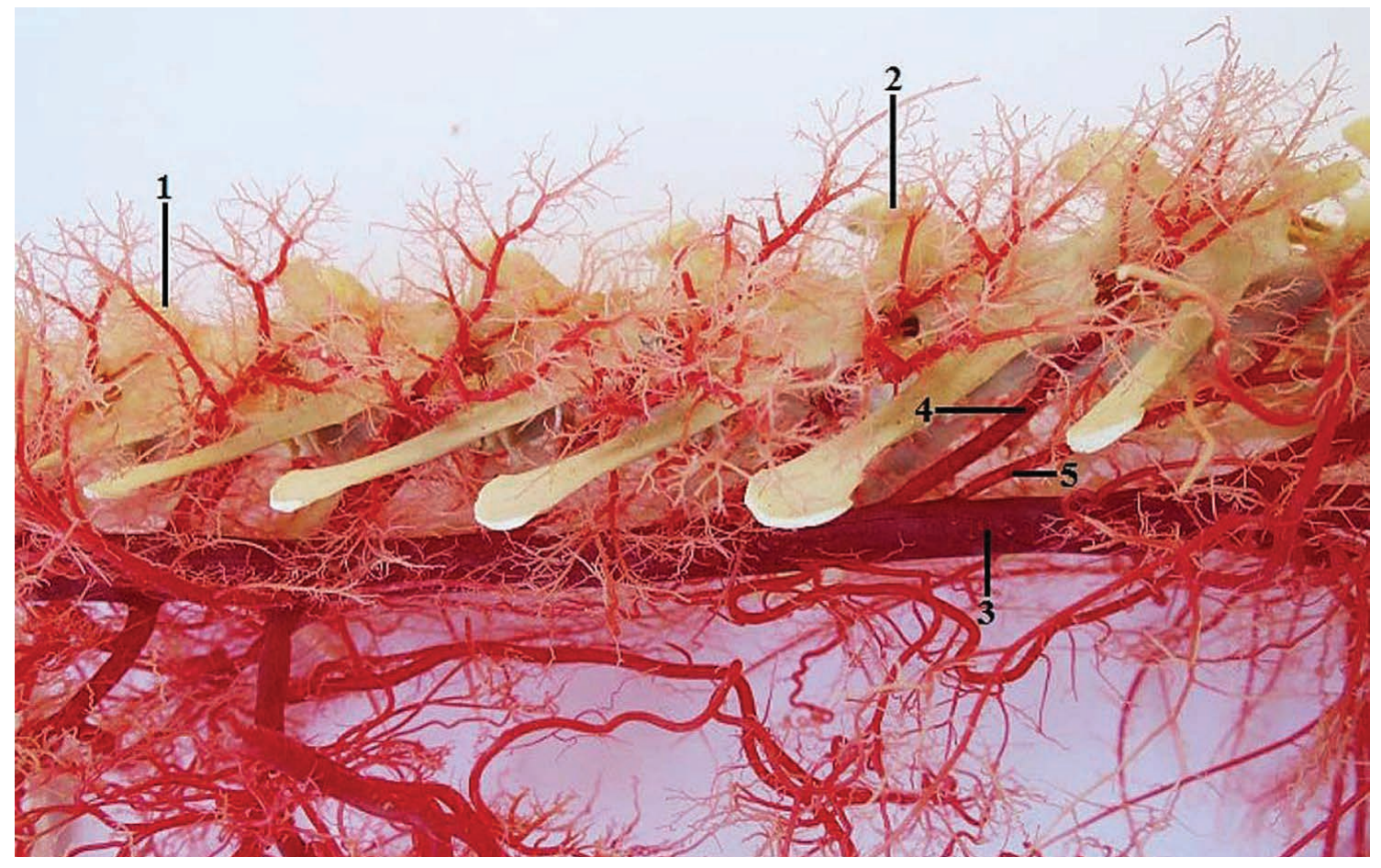

Fig. 2. Aa. lumbales and a. sacralis mediana in the hare. 1 -vertebra lumbalis $\mathrm{I} ; 2$-vertebra lumbalis $\mathrm{V}$; 3 -aorta abdominalis; $4-$ a. lumbalis V; 5 - a. sacralis mediana. Macroscopic image, lateral view

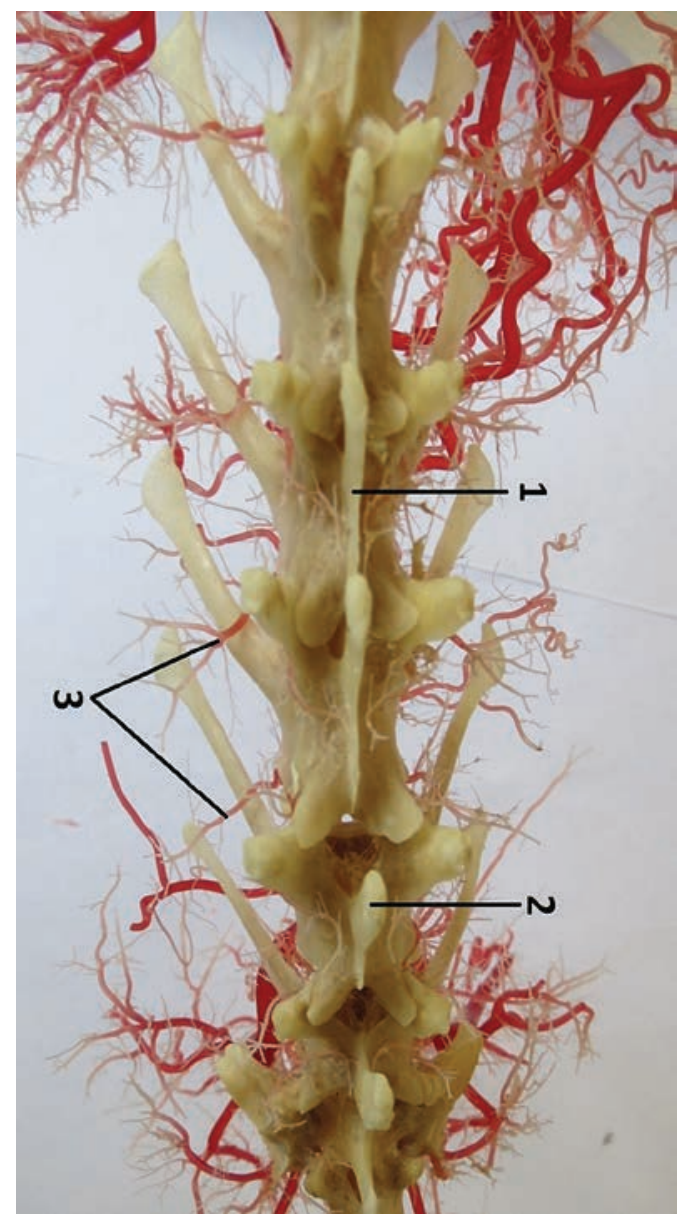

Fig. 3. Rr. dorsales arising from aa. lumbales in the rabbit. 1 -vertebra lumbalis IV; 2 - vertebra lumbalis VI; 3 - rr. dorsales. Macroscopic image, dorsal view 


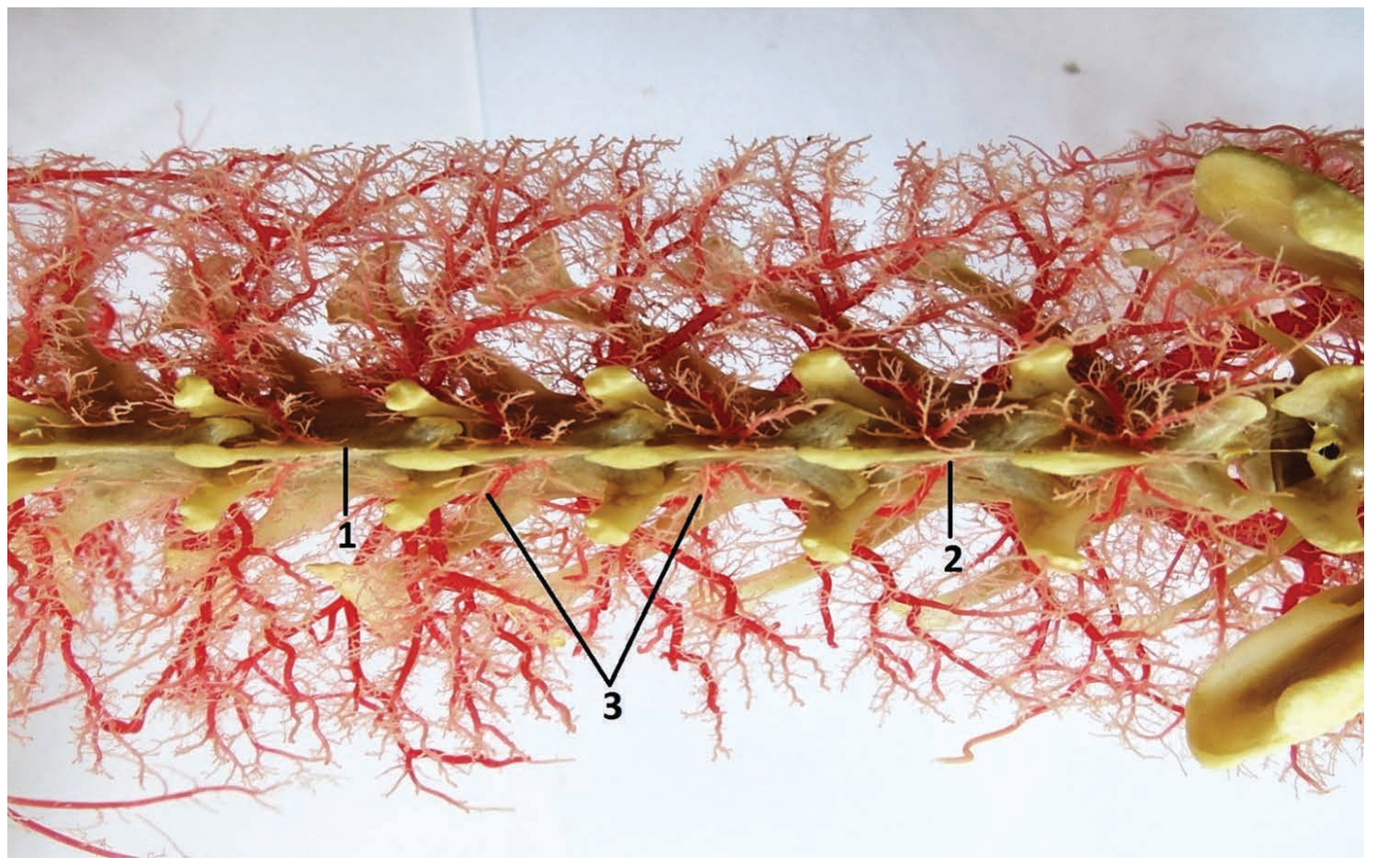

Fig. 4. Rr. dorsales arising from aa. lumbales in the hare. 1 -vertebra lumbalis III; 2 - vertebra lumbalis VI; 3 - rr. dorsales. Macroscopic image, dorsal view

ent in the first pair in $20 \%$ of the cases, in the first two pairs in $20 \%$ of the cases and in the first three pairs in $10 \%$ of the cases. In the remaining cases, the paired aa. lumbales originated by means of a common trunk at each level (Fig. 1). In the hare, the first pair originated independently in $20 \%$ of the cases and the first two pairs in $60 \%$ of the cases. In the remaining cases, the paired aa. lumbales originated by means of a common trunk at each level (Fig. 2). From the aa. lumbales arose $r r$. dorsales supplying the muscles of the body stem. In the rabbit, from each a. lumbalis arose $r r$. dorsales in number of 3-6 and in the hare in number of 7-9. Also their diameter, ramification and density were higher in the hare in comparison with the rabbit (Fig. 3, 4).

The $a$. sacralis mediana was the direct continuation of the aorta abdominalis. It ran ventrally to the sacrum, to reach the coccygeal vertebrae and continued caudally as a. caudalis mediana. In the rabbit, $a$. sacralis mediana originated from aorta abdominalis at the level of the 6th lumbar vertebra (Fig. 1). From a. sacralis mediana in the rabbit arose the last pair of aa. lumbales in $30 \%$ of the cases and last two pairs in $70 \%$ of the cases (Fig. 1). In the hare, the origin of $a$. sacralis mediana was located at the level of the 5 th lumbar vertebra in $60 \%$ of the cases (Fig. 2) and at the level of the 6th lumbar vertebra in $40 \%$ of the cases. From $a$. sacralis mediana in the hare originated the last pair of aa. lumbales in $20 \%$ of the cases and last two pairs in $80 \%$ of the cases (Fig. 2).

\section{DISCUSSION}

The knowledge of anatomical variations is important for radiological and surgical procedures in humans and other animals due to its practical and theoretical significance for experimental research and surgical practice in experimental and domesticated animals [11], [12], [16].

Six pairs of aa. lumbales with symmetrical origin from the dorsal surface of the aorta abdominalis were found in the rabbit [13]. Krause [9] described, in the rabbit, the aa. lumbales as branches arising from the dorsal surface of the aorta abdominalis by means of a common trunk. This arrangement was found by the aa. lumbales I-VI. The aa. lumbales VII were arising by means of a common trunk with an origin from $a$ sacralis mediana. This unpaired artery arose from the dorsal surface of the aorta abdominalis at the level of aortic bifurcation. Popesko et al. [13] described $a$. sacralis mediana in the rabbit as an independent branch arising from the dorsal surface of the aorta abdominalis. From the a. sacralis mediana arose the aa. lumbales 
VII. In the majority of cases in our study, the aa. lumbales arose by means of a common trunk and the a. sacralis mediana gave off the aa. lumbales VI et VII.

The well-developed $r$. dorsales arising from the aa. lumbales in the hare was the most visible interspecies difference in our study. These differences are associated with the way of life. The wild living hares are better and permanently trained. Training induces dimensional adaptions of the vascular system concerning the vessel diameter, distensibility, density and wall thickness in a proportional manner [7].

There is a very significant gap in the literature concerning the description of the arterial system in the European hare. The anatomical differences between familiar species will help to understand the behavioral differences in the wild and domesticated animals. We hope that this work will be the starting point for possible future studies in this research area. Such knowledge is also critical in comparative studies across species, as well as in the professional's daily practice [6].

\section{CONCLUSIONS}

A good understanding of the anatomical variations can facilitate surgical interventions, including the interpretation of a number of modern medical procedures of clinical interest, such as computed tomography and angiography [14]. Therefore, both the normal and variant anatomy of the region should be well known for accurate diagnosis, better treatment and avoidance of iatrogenic injuries during interventional vascular procedures.

\section{REFERENCES}

1. Abidu-Figueiredo, M., Xavier-Silva, B., Cardinot, T.M., Babinski, M. A., Chagas, M. A., 2008: Celiac artery in New Zealand rabbit: Anatomical study of its origin and arrangement for experimental research and surgical practice. Pesq. Vet. Bras., 28, 237-240.

2. Bednarova, Z., Malinovsky, L., 1986: Ramification of celiac artery in the domestic cat. Folia Morphol., 34, 36-44.

3. Brudnicki, W., Macherzyńska, A., Nowicki, W., 2007: Variation in the arteries of the aortic arch in European brown hare (Lepus Europaeus), Electronic Journal of Polish Agricultural Universities 10, http://www.ejpau.media.pl/volume10/issue1/art-03.html.

4. Brudnicki, W., Kirkillo-Stacewicz, K., Skoczylas, B., Nowicki, W., Jablonski, R., Brudnicki, A., Wach, J., 2015: The arteries of the brain in hare (Lepus europaeus Pallas, 1778). Anat. Rec., 298, 1774-1779.

5. Dabanoglu, I., 2000: A quantitative study of the aorta of the New Zealand rabbit (Oryctolagus cuniculus L.). Anat. Histol. Embryol., 29, 145-147.

6. Dugat, D., Rochat, M., Ritchey, J., Payton, M., 2011: Quantitative analysis of the intramedullary arterial supply of the feline tibia. Vet. Comp. Orthop. Traumatol., 24, 313-319.

7. Huonker, M., Schmid, A., Schmidt-Trucksäß, A., Grathwohl, D., Keul, J., 2003: Size and blood flow of central and peripheral arteries in highly trained able-bodied and disabled athletes. J. Appl. Physiol., 95, 685-691.

8. Koirala, S., Baral, P., 2012: A series of study of anatomic variation on arterial system. Webmed Central Anatomy, 3, 6. WMC003513. DOI: 10.9754/journal.wmc.2012.003513

9. Krause, W., 1884: Die Anatomie des Kaninchens in Topographischer und Operative Rücksicht. Verlag von Wilhelm Engelman, Leipzig, 383 pp.

10. Krešáková, L., Boldižár, M., Prokeš, M., 2011: Variations in branching of arteria mesenterica cranialis in rabbit. In Proceedings of the International Conference: Morfologie v Čechách a na Slovensku, Ostrava, Czech Republic, June 3, 75-78.

11. Krotscheck, U., Adin, C.A., Hunt, G.B., Kyles, A.E., Erb, H.N., 2007: Epidemiologic factors associated with the anatomic location of intrahepatic portosystemic shunts in dogs. Vet. Surg., 36, 31-36.

12. Mechirova, E., Zacharias, L., Jalc, P., Domorakova, I., 1999: Spinal cord white matter injury after single and repeated ischaemia/ reperfusion observed by a light microscope. Biologia, 54, 163-167.

13. Popesko, P., Rajtova, V., Horak, J., 1990: Anatomic Atlas of Small Laboratory Animals I (In Slovak). 1st edn., Príroda, Bratislava, $255 \mathrm{pp}$.

14. Saunders, A.B., Winter, R.L., Griffin, J.F., Thieman, K. M., Miller, M. W., 2013: Surgical management of an aberrant left subclavian artery originating from a left patent ductus arteriosus in a dog with a right aortic arch and abnormal branching. J. Vet. Cardiol., 15, 153-159.

15. Shively, M. J., Stump, J.E., 1975: The systemic arterial pattern of the guinea pig: the abdomen. Anat. Rec., 182, 355-366.

16. Swindle, M.M., Smith, A.C., Hepburn, B. J.S., 1988: Swine as models in experimental surgery. J. Invest. Surg., 1, 65-79.

17. Zamir, M., Wrigley, S. M., Langille, B.L., 1983: Arterial bifurcations in the cardiovascular system of a rat. J. Gen. Physiol., 81, 325-335.

Received April 21, 2016 